\title{
Tekstil Baskı Kalite Kontrolünün Görüntü İşleme Teknikleri ile Gerçekleştirilmesi* $^{*}$
}

\author{
Ahmet Çelik ${ }^{1 * *}$, Emre Tekin ${ }^{2}$ \\ ${ }^{1}$ Kütahya Dumlupınar Üniversitesi, Mühendislik Fakültesi, Bilgisayar Mühendisliği Bölümü, Kütahya, Türkiye (ORCID: 0000-0002-6288-3182) \\ ${ }^{2}$ Kütahya Dumlupınar Üniversitesi, Mühendislik Fakültesi, Bilgisayar Mühendisliği Bölümü, Kütahya, Türkiye (ORCID: 0000-0003-2189-9265)
}

(Konferans Tarihi: 5-7 Mart 2020)

(DOI: 10.31590/ejosat.araconf34)

\begin{abstract}
ATIF/REFERENCE: Çelik, A. \& Tekin, E. (2020). Tekstil Baskı Kalite Kontrolünün Görüntü İşleme Teknikleri ile Gerçekleştirilmesi. Avrupa Bilim ve Teknoloji Dergisi, (Özel Sayı), 268-276.

$\ddot{O} z$

Üretici firmaların ürünlerinin kaliteli olması gerekmektedir. Kalite, ürünlerin farklı özellikleri taşımasına bağlıdır. Kalite, üretilen ürünün hammadesine bağlı olduğu kadar tasarımına, montajına ve sonradan üzerine eklenen ürünlerin de bağlıdır. Tekstil üretimi Türkiye'de çok büyük ihracat payına sahiptir. Üretilen tekstil ürünlerinin hammaddesi olan ipliklerin kaliteli olması gerekir. Bu tekstil ürünlerinin üzerinde kullanılan baskı desenlerininde kaliteli olması büyük önem arz etmektedir. Tekstil baskılarının kusurlu olması kalitesiz defolu olmasına sebep olmaktadır. Bu baskılar tekstil sektöründe kumaş yüzeylerine uygunlanmakta ve baskı üzerindeki kusur hatası oluşursa büyük bir tekstil kumaşının kullanılamamasına neden olmaktadır. Tekstil yüzeyindeki bu kusurların geç fark edilmesi durumunda ise uretic fabrika açısından büyük bir maliyet kaybı ortaya çıkabilmektedir. Günümüzde tekstil ürünleri üzerinde baskı hata kontrolü çalışan personeller tarafından yapılmaktadır. Bu çalışmada; tekstil ürünleri üzerindeki baskıların kalite kontrol aşamasında, çalışanlar(insan) tarafından kontrol edilmesi yerine, yazılım ve donanım vasıtasıyla otomatik bir sistem tarafından yapılması için kullanılabilecek bir uygulama yapılmıştır. Kamera yardımıyla elde edilen kumaş görüntüleri üzerinde, piksel fark görüntü işleme tekniklerini kullanarak baskı kusurları tespit edilmiştir.
\end{abstract}

\section{Performing Textile Print Quality Control with Image Processing Techniques}

\begin{abstract}
Product quality must have one standard for production companies. Quality depends on the different characteristics of the products. Quality depends on raw material, design and installation of the product. Textile production have large share of export in Turkey. Yarns must be high quality for textile and printing on textile also important for textile products. Defect on printing makes whole product defected. This Prints used for textile surface. If defect on printing occur this may lead to whole product defected. Noticing late this defect could very high costs of product. Recently quality control made by employees. This work focused on making quality control by automatically software and hardware instead of employees. The print defects were detected by using pixel difference image processing techniques on the fabric images obtained with the help of the camera. The obtained values will effect last decision about image whether is acceptable or not. It will be more reliable if values are obtained by much more image processing techniques.
\end{abstract}

Keywords: Image processing, Defect detection, Pixel Difference, Quality control, Textile print

\footnotetext{
${ }^{*}$ Bu makale International Conference on Access to Recent Advances in Engineering and Digitalization (ARACONF 2020) de sunulmuştur.

** Sorumlu Yazar: Kütahya Dumlupınar Üniversitesi, Mühendislik Fakültesi, Bilgisayar Mühendisliği Bölümü, Kütahya, Türkiye, ORCID: 00000002-6288-3182, ahmet.celik@,dpu.edu.tr
} 


\section{Giriş}

Ülkemizde günümüzde üretim yapılan tesislerde çok fazla insan gücüne dayalı işlemler yapılmaktadır. Bilgisayar ve otomasyon sistemlerinin üretim süreçlerinde yer alması hem yapılan işi hafifletecek hem de daha doğru sonuçlar alınmasını sağlayacaktır. Özellikle maliyet ve hata payları göz önüne alınacak olursa bu konularda düşüş sağlamak üretim sürecine ve firmalara ciddi anlamda katkı sağlayacaktır.

Sanayi sektörü başta olmak üzere fabrikalarda üretilen ürünlerin hata kontrolünün yapılması gerekmektedir. Çünkü hatalı ürün üretimi fabrika sahiplerine büyük zararlar oluşturmaktadır. Hatalı ürünlerin üretildikten sonra müşterilere ulaştırılması ve fabrikalara hatalı ürünlerin iade edilmesi, üretici firmalar için büyük maliyet ve itibar kaybıdır. (Çelik, A. 2016). Sanayi alanında metal, alümiyum, demir, ray, saç, tekstil ürünleri üzerinde üretim aşamasında kusurlar oluşabilmektedir.

Fabrikalarda üretilen ürünlerin ilk aşamada hızlı kalite kontrolünün yapılması çok büyük önem arz etmektedir. Hatalı ürünün kısa sürede tespiti gerçekleşirse fabrika anında çözüm mekanizmasını devreye sokabilmektedir. Günümüzde birçok üretici kalite kontrolünü çalışan personeller tarafından gözle kontrol ederek gerçekleştirmektedir. Ancak bilgisayar destekli akıllı bir görüntü işleme sistemiyle, üretilen ürünlerin görüntüleri üzerinden, hızlı bir kalite, kusur kontrol sistemin olması büyük fayda sağlayabilir(Çelik, A. 2016), ( Orak, İ. M. \& Çelik, A. 2017).

E. Karami ve arkadaşları yaptıkları çalışmadaSIFT, SURF, BRIEF algoritmaları hakkında bilgi vermişler ve bu algoritmalar arasındaki performans farklılıkları işlemişlerdir. Bu algoritmalar birden fazla görselin birbirine benzeyip benzemediğini bulan algoritmalardır. Yapmak istediğimiz projenin uygulanma kısmında hız çok önemli bir etkendir bu yüzden en hızlı şekilde işlemin yapılması gerekmektedir(Karami, E. Prasad, S. \& Shehata, M. 2015).

A. Serdaroglu ve arkadaşları yaptıkları çalışmada, bez üzerindeki hatalar üzerinde durulmuştur. Wavelet transform kullanılarak oluşturulan kalite kontrol algoritmasından yararlanılabilir (Serdaroglu, A. , Ertuzun, A. \& Ercil, A. 2016). N. Jayanthi, Genel olarak feature detection'dan bahsedilmiş ve Blob detection, Template matching, Surf feature detection teknikleri 7 özelliğine göre farklı görsel örnekleri ile karşılaştırılmıştır(Jayanthi, N. \& Sreedevi, I. 2018). S.Anitha, Görsel üzerinde Contrast, Adjustment, Intensity adjustment, Histogram equalization, Binarization ve Morphological operation teknikleri kumaş üzerindeki defolu kısımların tespit edilmesini kolaylaştırma açısından birbiri ile karşılaştırılmış(Anitha, S. \& Radha, V. 2010) .

Oni, D.I., Tekrar eden desenlerin kullanıldığı kumaşlarda hata kontrolü yapmak amacıyla sınıflandırma algoritmaları kullanılarak sonuca ulaşılmaya çalışılmıştır(Oni, D.I., Ojo, J.A*., Alabi, B.O., Adebayo, A.A., \& Amoran, A.E). Qiulin C. , Tekstil ürünü üzerinde lokal hataların bulunmasına yönelik yapılmış bu çalışmada Gauss piramidi ve Seçici arama (Selective search metotları) kullanılmıştır(Chena, Q., Jessomeb, R., Maggardb, E. \& Allebacha, J. P.). Kazım Hanbaya Bu makalede kumaş hata tespitinde kullanılacak Kamera lens, 1şı ve poz yakalayıcı (Frame Grabber) seçimi üstünde durulmuş bununla birlikte yapısal yaklaşımlar, istatistiksel yaklaşımlar, spectral (Wavelet, Fourier, Gabor transform teknikleri) yaklaşımlar, model tabanlı yaklaşımlar , öğrenme tabanlı yaklaşımlar, hibrit olarak bu yaklaşımların hata tespitinde kullanılması değerlendirilmiştir(Hanbaya, Kazım., Talub, M. F. \& Özgüvenc, Ö. F.).

$\mathrm{Bu}$ projede herhangi bir tekstil ürününün üzerine yapılan fabrikasyon baskı boya işleminin kalite kontrol aşamasında uyarı ve destek yapılması amacıyla orijinal görüntü ile baskısı yapılmış görüntünün karşılaştırılması amaçlanmıştır. Bu noktada konumuz nevresim ürünü ile sınırlandırılacaktır. Bunun sebebi hem örnek görüntülerin nevresim baskısı yapan bir firma tarafından alınması hem de nevresim ürününün bir bant şeklinde aralıksız olarak sarılması ve bu aşamada kamera aracılığıyla bant üzerinden daha kolay veri alınmasıdır.

\section{Materyal ve Metot}

\subsection{Grayscale}

Renkli görüntünün pikselleri gri tona çevrilir. 3 farklı gri değere dönüştürme gerçekleştirilebilir. En yayın kullanılan yöntem ortalama gri değere dönüştürme işlemidir.

\subsection{Template matching}

Orijinal resimdeki bütünden parçanın hangi kısımda olduğunu anlamak gerekiyor bu teknik kullanılarak hangi parça olduğu gösterilir.

\subsection{Pixel Difference}

Piksel farklarının mutlak değerini alıp aradaki fark matematiksel bir ifadeye koyarak bir benzerlik değeri bulabileceğiz.

\subsubsection{Pixel difference kod uygulamast}

Karşılaştırılacak görsellerin boyutları alınıyor. Burada dikkat edilmesi gereken nokta aynı boyutta olmalarıdır. Şekil 1 üzerinde karşılaştırılacak iki görüntünün boyutları, ilgili değişkenlere atayan kod görülmektedir. 


\section{Avrupa Bilim ve Teknoloji Dergisi}

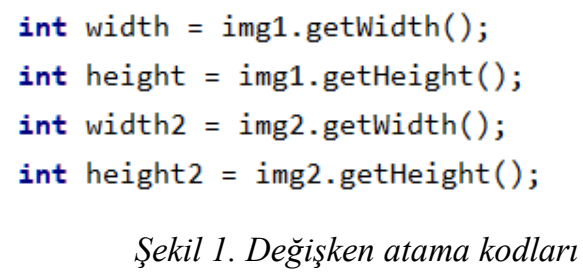

Şekil 1. Değişken atama kodları

$\mathrm{Bu}$ işlem basamağından sonra eğer görseller kriterlere uygunsa matris yöntemi ile x,y düzleminde hareket edilerek piksellerin tek tek RGB (Red:Kırmızı, Green:Yeşil, Blue:Mavi) değerleri alınarak karşılaş̧ııılıyor(Şekil 2).

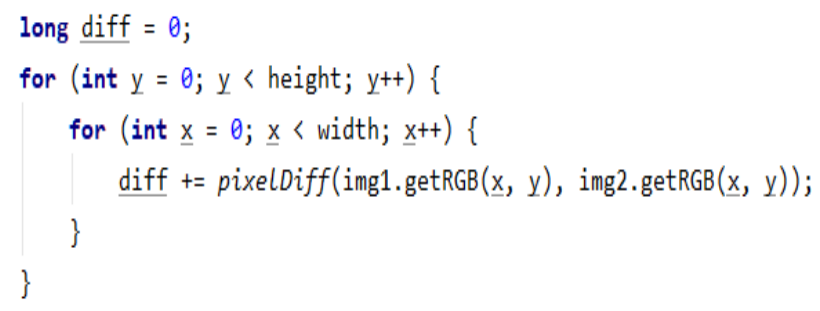

Şekil 2. RGB değerlerinin karşılaştırma kodu

\subsubsection{Piksel difference işlemi}

Burada R, G, B değerlerini ayrı ayrı elde etmek için Rigth Shift işlemi uygulanıyor. Binary değerler R, G, B için 16 bit kaydırılıp ilk 8 bit'in sona gelmesi sağlanıyor.

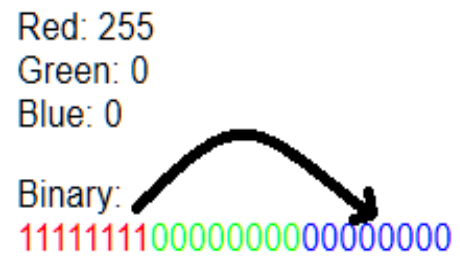

\section{Şekil 3. Shift işlemi}

Kaydırma işleminden sonra \& 0xff işlemi ile kaydırmış olduğumuz R, G, B değerlerini elde etmiş oluyoruz. 0xff işlemi kaydırılan değeri AND işlemine sokarak ilk 16 bit'in kaldırılmasına sadece ihtiyacımız olan değer kısmını elde etmemizi sağlar.

Şekil 4. Oxff işleminin uygulanışl

Aşağıdaki kodlar ile bu işlemi tüm R,G,B değerleri için uygulanır. Elde edilen değerler mutlak değer içerisinde bir birinden çıkararak farkları toplayıp değeri tüm piksel'lerin farklı olma durumuna göre karşılaştırarak arasındaki farklılık ne kadar küçükse iki görüntü arasında benzerlik o kadar fazladır.

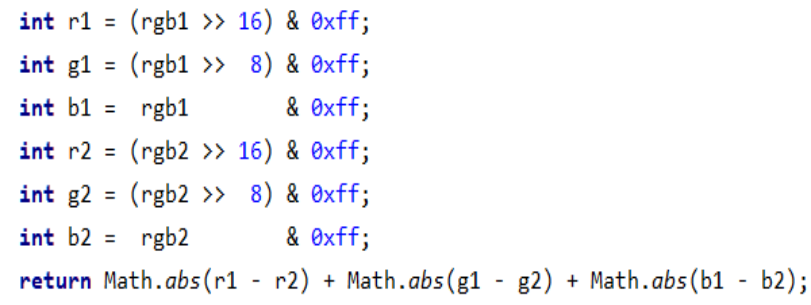

Şekil 5. RGB değerlerinin üzerinde Shift işlemi ve iki görüntünün karşılaştırllması 


\subsection{Algoritma Tanımı}

$\mathrm{Bu}$ çalışmanın gerçekleştirilme aşamalarından en önemlisi, uygun görüntünün kaliteli kameralar yardımıyla elde edilmesine bağlıdır. Eğer elde edilen görüntüler üzerinde istenmeyen pikselleşmeler varsa belirli oranda bulanıklaştırılmalı, açıklık değeri, zıtlık değeri ayarlanarak hatalı pikselleştirilmelerin önüne geçilmesi başarı oranını arttıracaktır(Wang, Z., Bovik, A. C., Sheikh, H. R. \& Simoncelli E. P. ).

Bu çalışmada en önemli diğer adım ise tekstil üzerindeki kusur tesptini yapacak yöntemdir. Kusur tespiti için Orak, I.M ve Çelik A. ray yüzeylerindeki kusur tespitlerini geliştirdikleri COLMSTD algoritmasıyla yapmışlardır(Çelik, A. 2016)(Orak, İ. M. \& Çelik, A. 2017). Ancak SIFT, MSE ve KNN gibi diğer yöntemlerde görüntü üzerinde kusur tespitleri için kullanılabilir.

\subsubsection{SIFT}

Bölgesel özellikleri tanıyarak karşılaştırmada daha doğru sonuca ulaşmamızı sağlayacaktır(Laganière, R. 2011) .

\subsubsection{MSE}

Görüntü karşılaştırmada hataların karelerinin ortalamasını ölçer - yani, tahmini değerler ile gerçek değer arasındaki ortalama kare farkıdır(Laganière, R. 2011).

\subsubsection{KNN}

Makine öğrenmesinde kullanılan sınıflandırma yapmaya yarayan algoritmadır. Proje hayata geçirildiğinde örneklemler verilerek sistemin kalite kontrol yapması ve daha doğru sonuçlara ulaşmak için gerekli bir tekniktir(Peterson, L. E. 2009) .

\subsubsection{Canny edge detector}

Resimlerin kenarlıklarının çıkarılmasını sağlar. Uygulama Java dilinde programlanacaktır. Bununla birlikte Open CV Kütüphanesi kullanılarak görüntü işleme teknikleri uygulanacaktır(Laganière, R. 2011).

\subsection{Algoritmanın Akış Şeması}

Yapılan bu çalışmada elde edilen görüntü üzerinde planlanan işlem basamaklarının uygulanması gerekmektedir. Şekil 6 üzerinde uygulamanın genel akışı verilmiş olup farklı teknikler sırasıyla uygulanıp sonuçlar alınabilir. Burada piksel difference(Piksel Fark) yöntemi kullanılmıştır Burada ayrıca kenarlık tespiti kullanılacak olup alınan sonuçlar daha geliştirilecektir.

Algoritmada birinci adımda kumaş yüzeyindeki desenin görüntüsü alınacaktır. İkinci adımda kenarlık tespiti yapılarak desenin sınırları çizilecektir. Ancak bu seçenek kullanıcı seçimine bağlı olacaktır. Üçüncü adımda gerçek desenin(ana desen) kumaş yüzeyinde varlığı kontrol edilir. Aslında gerçek desen ile kumaş yüzeyindeki konumu tespit edilir. Dördüncü adımda ise benzerlik oranı hesaplanır. Burada piksel fark yöntemi kullanılmıştır. Beşinci adımda ise sonuçlar form üzerinde gösterilir. Altıncı adımda algoritmanın bitirilir.

Uygulama sonucunda yüzdelik cinsinden 0 (sıfır)a yakın farklılık varsa, gerçek desen ile kumaş yüzeyindeki farklılık az demektedir ve kusur oranı azdır. Farklılık çok ise baskı kalitesinde bozukluk var demektedir.

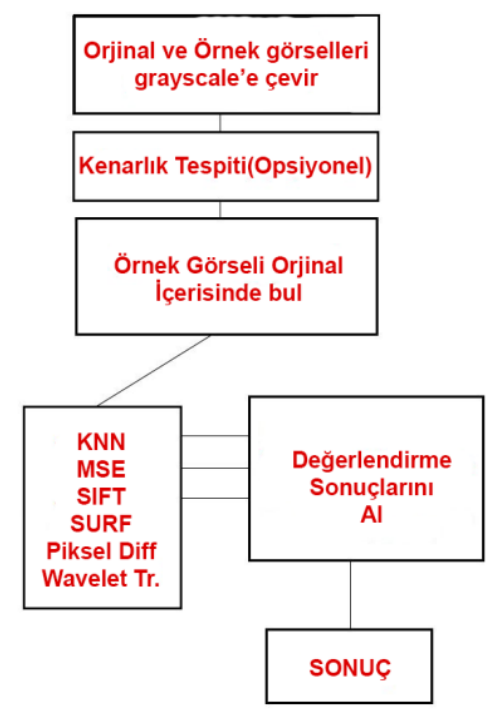

Şekil 6. Uygulama Algoritmasının Genel Yapısl 
Uygulamada kullanılacak olan fabrikadan ve alınmış basımı yapılmış örnek nevresim örneği ile değerlendirilecektir(Şekil 7). Desenler 240x64 cm boyutlarındaki kumaşlara uygulanır.

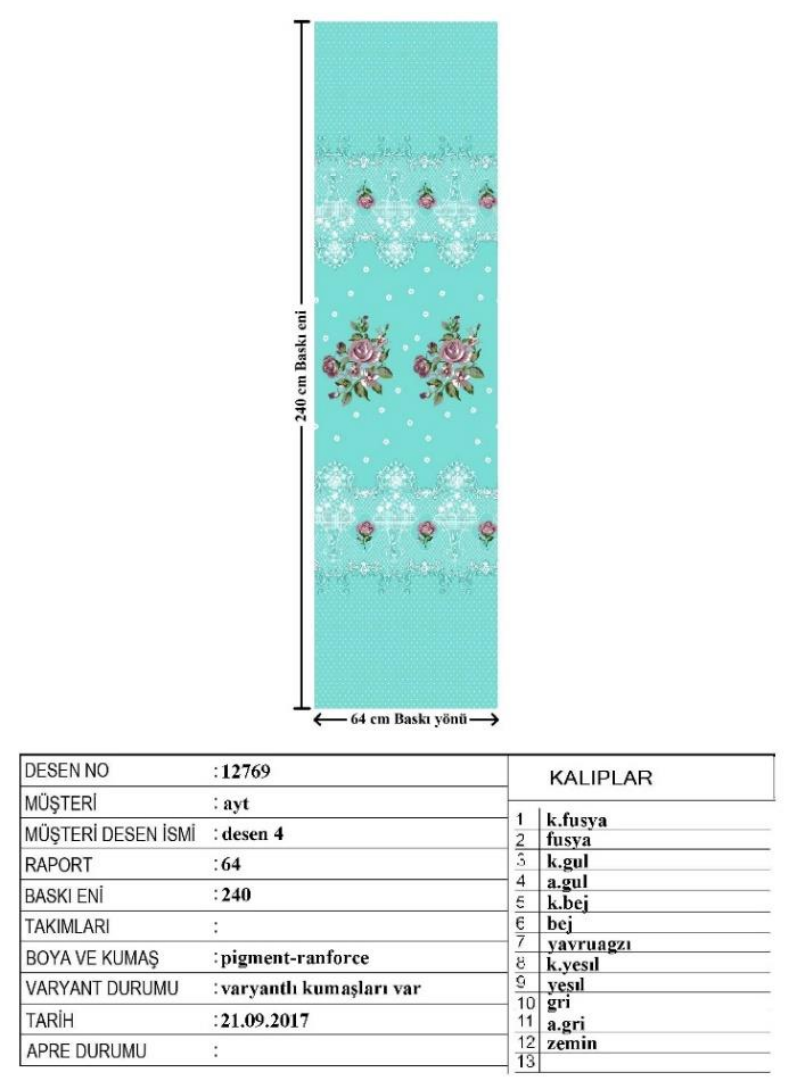

Şekil 7. Örnek bir orijinal nevresim deseni

Şekil 8’te basımı yapılmış iki görüntü verilmiştir. Görüntülerden biri siyah zemine diğeri beyaz zemine konumlandırılmıştır.

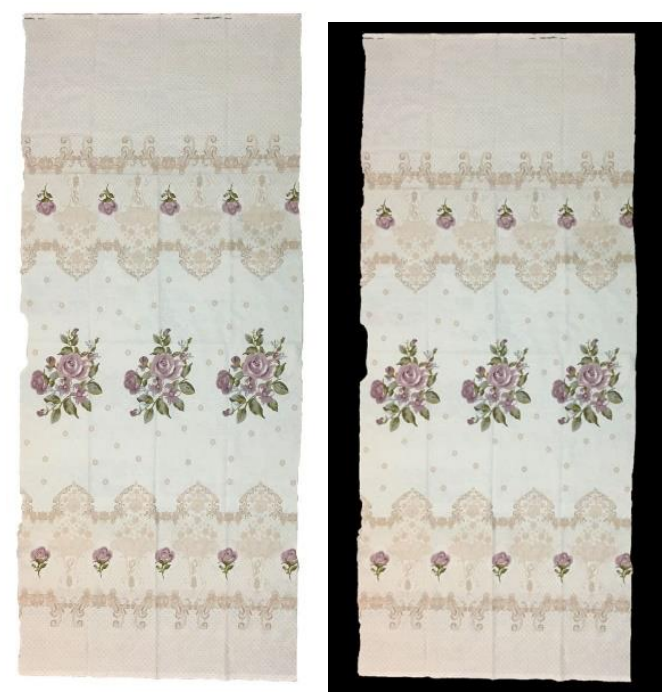

Şekil 8. Fabrikadan alınmış basım yapılmış nevresim görseli

Bununla birlikte test olması açısında örnek görüntüler; 


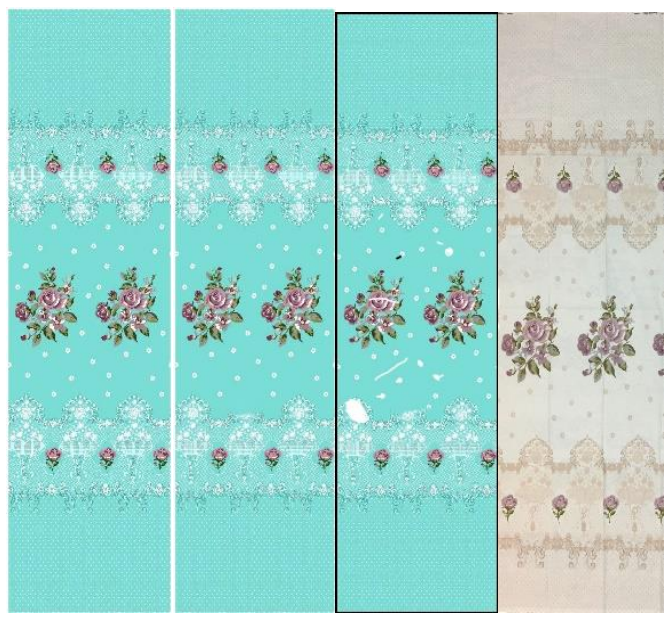

Şekil 9. Örnek görseller

Aşağıda kullanılan görsellerin açıklamaları mevcuttur.

Tablo 1. Görsel açıklaması

\begin{tabular}{|l|c|}
\hline \multicolumn{1}{|c|}{$\begin{array}{c}\text { Görüntü } \\
\text { Tanımı }\end{array}$} & Görüntü Özelliği \\
\hline Main.png & Şablon Görsel \\
\hline Hatali1.png & Az Farklılık içeren \\
\hline Hatali3.png & Çok farklılık içeren \\
\hline Hatali2.png & Renk ve şekil farklılıkları \\
\hline
\end{tabular}

\subsection{Uygulama Gerçekleştirme}

Şekil 10 üzerinde Grayscale çevirme işlemi uygulanmış görseller;

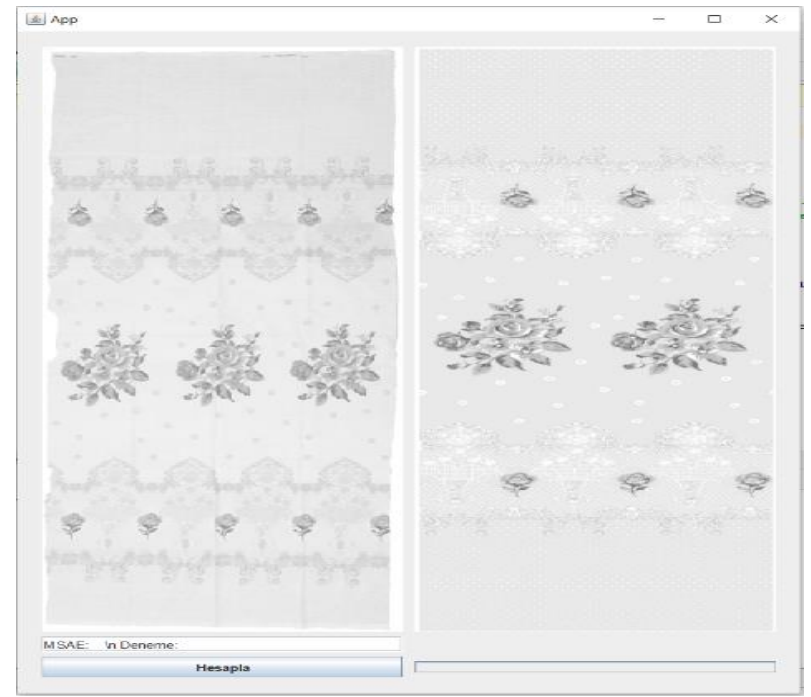

Şekil 10. Grayscale çevrilmiş görseller

Şekil 11'de piksel farklılığı kullanılarak alınmış sonuç mevcuttur(hatali3.png). Sonuç : \%3,55 farklılıktır. 
Avrupa Bilim ve Teknoloji Dergisi

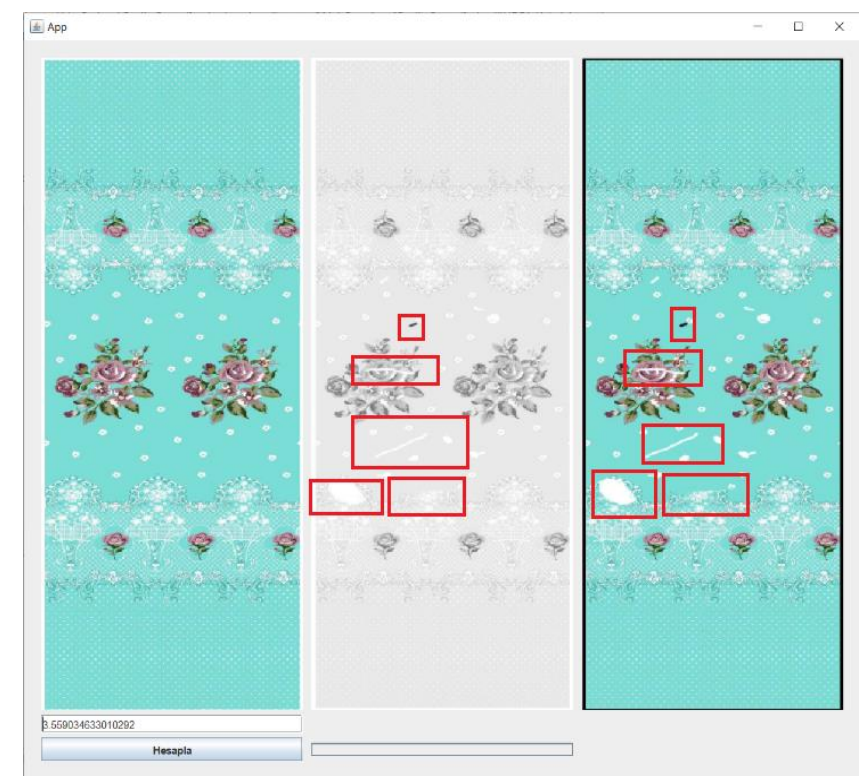

Şekil 11. Yüksek hata içeren görseller

Yine aynı algoritma kullanılarak daha az hata içeren görsel (hatali1.png) kullanılarak alınan sonuç ise $\% 0,16$ farklılık olmuştur.

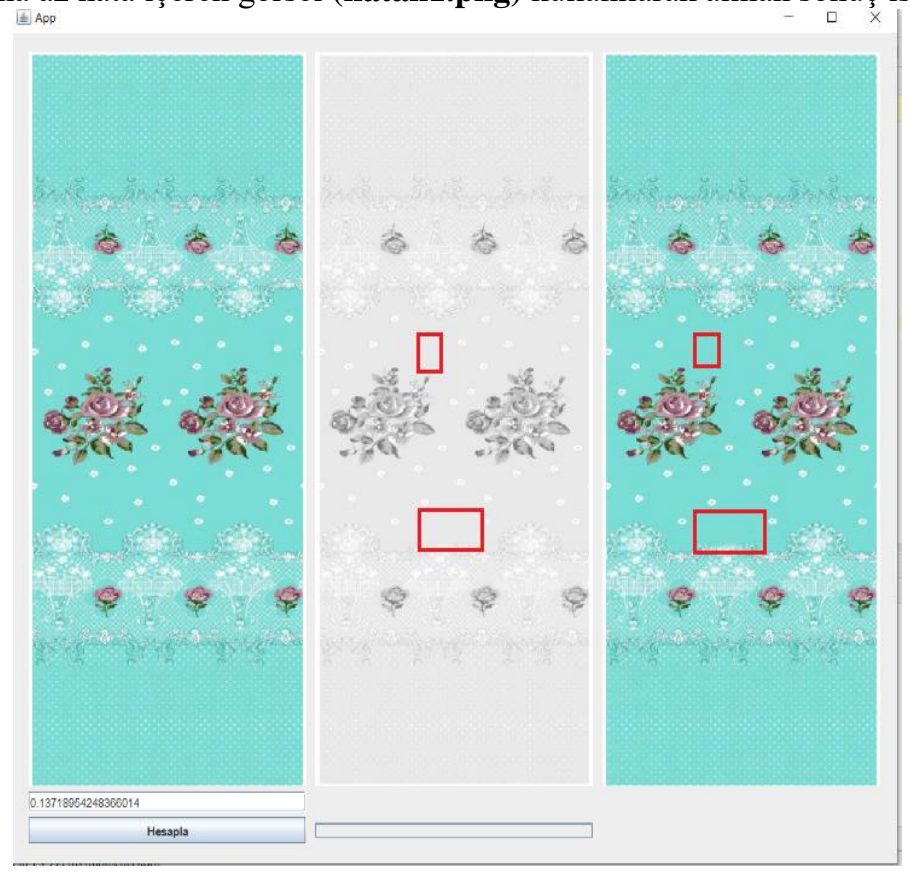

Şekil 12 Düşük hata içeren görseller

\subsubsection{Canny Edge Detector Kullanularak Pixel Difference Uygulamast}

$\mathrm{Bu}$ uygulamada örnek görseller üzerinde ilk önce Canny Edge Detector kullanıyoruz. Aldığımız sonuç görselleri tekrar pixel difference uygulayarak sonuçları gözlemliyoruz. 
European Journal of Science and Technology

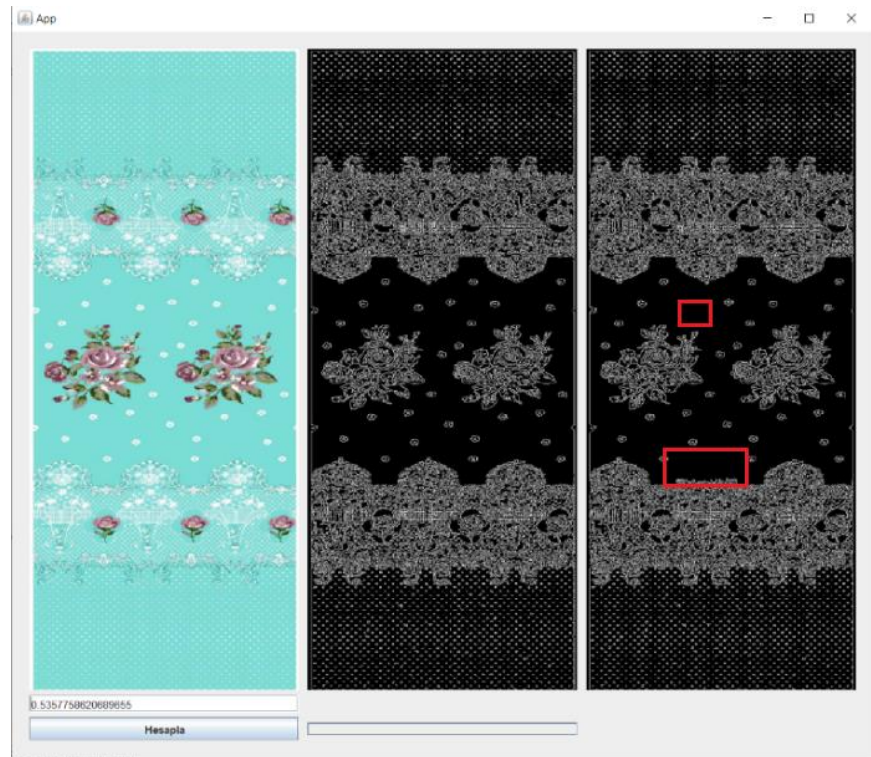

a-)

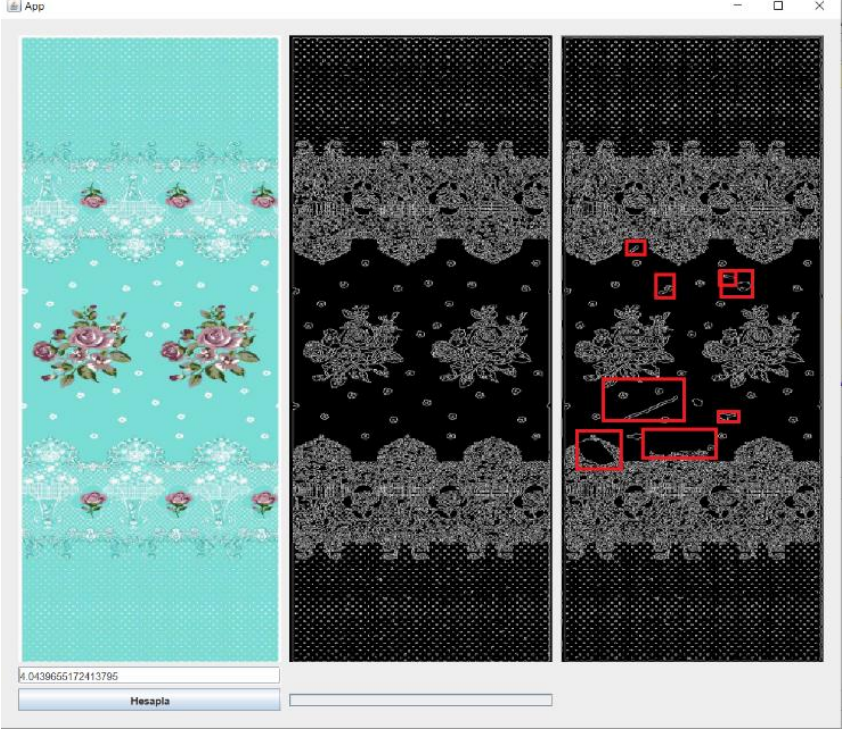

b-)

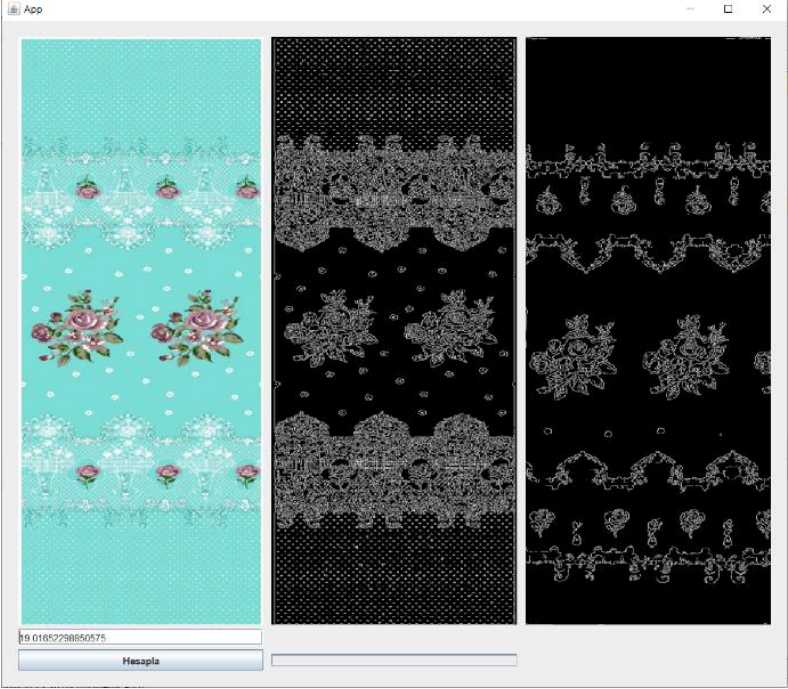

c-)

Şekil 13. a,b,c Desen üzerinde Kenar Tespiti yapılarak kusurlu değer bulma 


\section{Araştırma Sonuçları ve Tartışma}

\subsection{Karşılaşılan Zorluklar}

Yapılan çalışmada desen hizalamalarının düzgün olması gerekmektedir. Bu yüzden kumaş yüzeyinden görüntü alınma aşamasında desenin başlangıç ve bitiş noktaları doğru işaretlenmeli ve görüntü kamera ile buradan doğru uzaklıklarda alınmalıdır. Bu çalışmada çok tercih edilen Template matching yöntemi uygulanmış ancak uygulamada tam istenilen sonuç alınamamıştır. Kumaş deseni görseli içersinde, verilen gerçek desen örneğinin yeri istenilen ölçüde bulunamamıştır. Bu engel farklı nesne tanıma algoritmalarıyla çözümlenmeye çalışllacaktır.

\subsection{Bulgular}

Yapılan çalışmadaki bulgular piksel difference işleminin hataları saptamak adına kullanılabileceğini ortaya koymaktadır. Yüksek hata içeren ürünlerde az olana göre değer yükselmiştir. Bu değer kenar tespit uygulanarak daha da artmıştır. Burada yapılabilecek işlem firmaların uygulamalarında hataları ne derecede önemsedikleri ne gibi durumlarda uyarı sisteminin harekete geçirileceği bilgisini almak ve bu bilgiye göre sınırları oluşturmak olacaktır.

\subsection{Tartışma}

Yapılan çalışmaların yoğun olarak tekstil ürünlerinin dokuma kalitesi konusunda olduğu anlaşılmaktadır. İplik dokuması hataları, yanlışşekilde örülmüş bölümler, delinme, yırtılma gibi bölümlerin saptanması konusunda başarılı sonuçlar verdiği görülmektedir. Bu çalışmalarda kullanılan tekniklerden faydalanılabilir. Baskı konusunda piksel difference tekniği örneklerden anlaşılacağı üzere anlamlı bir bilgi vermektedir. Bu teknik ile birlikte kullanılacak amaca yönelik farklı teknikler uygulamada daha doğru sonuçlar üretmemizi sağlayabilir.

\section{Sonuç}

Ülkemizde tekstil alanında üretimin yoğun olması ve görüntü işleme tekniklerinin ilerlemiş olması bu iki alanın ortak bir paydada daha sık buluşabileceğini gösteriyor. Tekstil firmalarında kalite kontrol anlamında otomasyon çok fazla bulunmuyor bu konuda yabancı otomasyonlar mevcut fakat yerli üretim yukarıdaki teknikler ilerletilerek uygulanabilir durumdadır.

\section{Kaynakça}

Çelik, A. (2016). Haddeleme İşlemi Sırasında Ray ve Profil Yüzeylerinde Oluşan Kusurların Tespit Edilmesine Yönelik Paralel İşlemci Uygulaması. Karabük Üniversitesi, Fen Bilimleri Enstitüsü.

Orak, İ. M. \& Çelik, A. (2017). Üretim aşamasında ray ve profilde oluşan kusurların tespitine yönelik bir paralel kusur algılama algoritmas1, Journal of the Faculty of Engineering and Architecture of Gazi University, 32 (2,): 439-448.

Karami, E. Prasad, S. \& Shehata, M. (2015) Image Matching Using SIFT, SURF, BRIEF and ORB: Performance Comparison for Distorted Images. Conference: 2015 Newfoundland Electrical and Computer Engineering Conference.

Serdaroglu, A. , Ertuzun, A. \& Ercil, A. (2016) Defect Detection in textile fabric images using wavelet transforms and independent component analysis. Pattern Recognition and Image Analysis., pp. 16(1):61-64

Jayanthi, N. \& Sreedevi, I. (2018) Comparison of Image Matching Techniques.

Anitha, S. \& Radha, V. (2010) Comparison of Image Preprocessing Techniques for Textile Texture Images.

Oni, D.I., Ojo, J.A*., Alabi, B.O., Adebayo, A.A., \& Amoran, A.E. Patterned Fabric Defect Detection and Classification (FDDC) Techniques: A Review.

Chena, Q., Jessomeb, R., Maggardb, E. \& Allebacha, J. P. Segmentation-Based Detection of Local Defects on PrintedPages

Hanbaya, Kazım., Talub, M. F. \& Özgüvenc, Ö. F. Fabric defect detection systems and methods-A systematic, literature review.

Wang, Z., Bovik, A. C., Sheikh, H. R. \& Simoncelli E. P. Image Quality Assessment: From Error Visibility to Structural Similarity.

Laganière, R. (2011) OpenCV Computer Vision Application Programming Cookbook, PACKT Publishing, Birmingham-Mumbai, 10200.

Peterson, L. E. (2009) K-nearest neighbor. [Online]. Available:http://scholarpedia.org/article/K-nearest_neighbor 